\title{
MEASUREMENT OF RADIOCARBON CONTENT IN LEAVES FROM SOME JAPANESE SITES
}

\author{
Yasushi Muraki ${ }^{1} \cdot \operatorname{Kimiaki}$ Masuda $^{1,2} \cdot \operatorname{KhA~Arslanov~}^{1,3} \cdot$ Hiroaki Toyoizumi $^{1}$ \\ Masataka Kato ${ }^{1}$ ' Yukiko Naruse ${ }^{1}$ 'Takuya Murata ${ }^{1}$ 'Tohru Nishiyama ${ }^{1}$
}

\begin{abstract}
We have measured radiocarbon contents in leaves collected from 15 sites in Japan, including mountain areas and big city areas for last three years. Comparing the radiocarbon contents in various areas, high ${ }^{14} \mathrm{C}$ concentrations $(80$ $100 \%$ as $\delta^{14} \mathrm{C}$ ) are seen for the leaves from the mountain and country sites. On the contrary, low concentrations (5-40\%o) were observed for the leaves from city region, especially near the road with heavy traffic. These results indicate that the atmosphere of the mountain and country sites in Japan is still clean but the $\mathrm{CO}_{2}$ gas coming from fossil non-radioactive carbon significantly pollutes the atmosphere of the city sites. The value of $\delta^{14} \mathrm{C}$ for the mountain areas implies that ${ }^{14} \mathrm{C}$ produced by nuclear bomb test in 1960s still remains. The decrease of $\delta^{14} \mathrm{C}$ at heavy traffic sites in Tokyo is consistent with the increase of $\mathrm{CO}_{2}$ concentration in the atmosphere assuming that almost all $\mathrm{CO}_{2}$ gas in this region originates from the fossil fuel.
\end{abstract}

\section{INTRODUCTION}

Natural radiocarbon on the Earth is produced by high-energy cosmic rays mainly in the upper atmosphere. Its content in the stratosphere and that in the troposphere would be in equilibrium according to the production rate by cosmic rays and the exchange rate of carbon between other reservoirs such as the ocean and the biosphere. However, such equilibrium has been interfered by the anthropogenic production of the excess radiocarbon and also dilution by non-radioactive (dead) carbon. The former is produced by atomic bomb tests in the atmosphere in 1950s and 1960s and also by nuclear power plants. Utilization of label isotopes at medical and research institutions may also contribute. The latter is originated from increase of carbon dioxide consisting of dead carbon as a result of fossil fuel combustion. It is very important to investigate both effects from environmental points of view.

Since the late 19th century after the industrial revolution, the concentration of carbon dioxide with dead carbon has been extensively increased and the contents of radiocarbon have been diluted (Suess effect). In 1950s and early 1960s, many atomic bomb tests were carried out until the test ban treaty was adopted in 1963. Soon after that, the content of ${ }^{14} \mathrm{C}$ in the atmosphere of the Northern Hemisphere was peaked and decreased slowly $(\tau=16 \mathrm{yr})$. Even in 1990s, the effect of the bomb tests still remains and the excess of ${ }^{14} \mathrm{C}$ to the pre-bomb level is $10 \%$ or more (McNeely 1994; Levin and Kromer 1997; Muraki et al. 1998). Environmental measurements of atmospheric ${ }^{14} \mathrm{CO}_{2}$ concentration have been done at several stations in Europe, Canada, Far East of Asia, and so on. Some researchers directly measure ${ }^{14} \mathrm{C}$ contents in atmospheric $\mathrm{CO}_{2}$ (Meijer et al. 1995; Nydal and Lövseth 1996; Levin and Kromer 1997; Kuc and Zimnoch 1998) and the others measure mainly those in plants (McNeely 1994; Muraki et al. 1998; Krajcar-Bronić et al. 1998; Leung et al. 1998).

We are interested in more local variation of radiocarbon contents as an indication of fossil fuel consumption. Some kinds of tree leaves are essentially yearly growing material, which incorporate carbon dioxide from the atmosphere of its surrounding environment. Since anthropogenic carbon dioxide is emitted from industrial facilities, traffic vehicles and human daily life and originates from fossil fuel, it does not include radiocarbon whose radioactive half-life is 5730 years. Environmental materials like tree leaves in large cities may have smaller concentration of radiocarbon, compared

\footnotetext{
${ }^{1}$ Solar-Terrestrial Environment Laboratory, Nagoya University, Furo-cho, Chikusa-ku, Nagoya 464-8601, Japan

${ }^{2}$ Corresponding author. Email: kmasuda@ stelab.nagoya-u.ac.jp.

${ }^{3}$ On leave from Geographical Research Institute, St. Petersburg University, Sredniy Prospect 41, St. Petersburg 199004, Russia
}

(C) 2001 by the Arizona Board of Regents on behalf of the University of Arizona RADIOCARBON, Vol 43, Nr 2B, 2001, p 695-701

Proceedings of the 17 th International ${ }^{14} \mathrm{C}$ Conference, edited by I Carmi and E Boaretto 
with the clean air. Thus concentration of radiocarbon would reflect the concentration of the local environmental carbon dioxide.

We have measured ${ }^{14} \mathrm{C}$ contents in fallen-leaves collected from several sites in Japan for last three years as the environmental monitor. Radioactivity of ${ }^{14} \mathrm{C} \beta$-decay was measured by a liquid scintillation counting (LSC) system. In this paper, the apparatus and measured results are reported and a possibility of environment monitoring by radiocarbon is discussed.

\section{SAMPLES}

The 17 samples of the leaves were collected from 15 sites of Japan, including mountain areas, country site and city areas, for the last three years as shown in Figure 1. The leaves from the mountain areas were collected at Agematsu $\left(35^{\circ} 45^{\prime} \mathrm{N}, 137^{\circ} 34^{\prime} \mathrm{E}, 1300 \mathrm{~m}\right.$ above sea level) and Norikura $\left(36^{\circ} 07^{\prime} \mathrm{N}, 137^{\circ} 08^{\prime} \mathrm{E}, 1450 \mathrm{~m}\right.$ asl). The leaves from the country site were sampled at Asahikawa $\left(43^{\circ} 46^{\prime} \mathrm{N}, 142^{\circ} 25^{\prime} \mathrm{E}, 130 \mathrm{~m}\right.$ asl) in Hokkaido. The leaves from the city areas were gathered from Tokyo $\left(35^{\circ} \mathrm{N}, 139^{\circ} \mathrm{E}, 20-60 \mathrm{~m}\right.$ asl) and Nagoya $\left(35^{\circ} \mathrm{N}, 137^{\circ} \mathrm{E}, 0-70 \mathrm{~m}\right.$ asl). All samples are yearly-fallen leaves of the hardwood such as the Zelkova serrata and the Quercus variabilis.

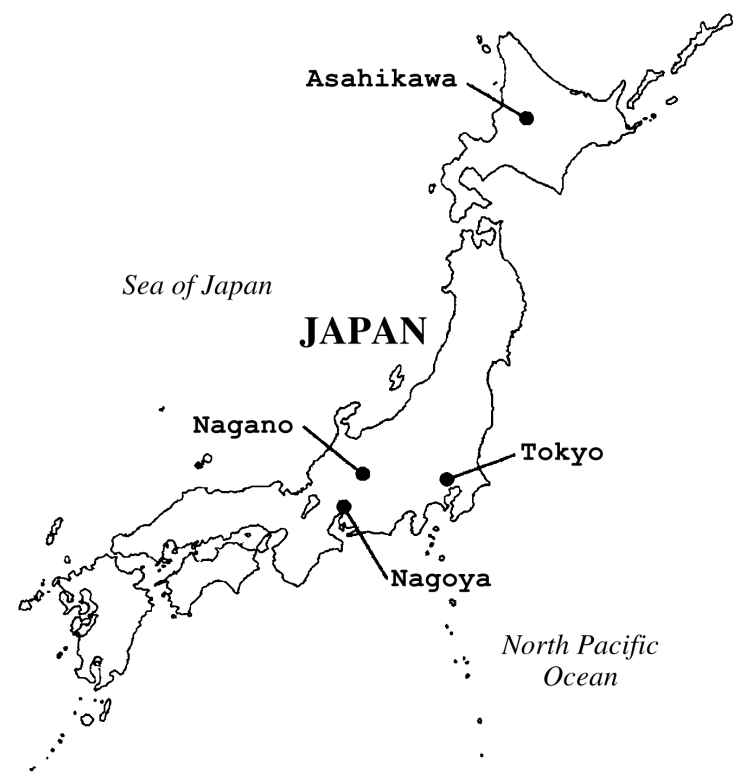

Figure 1 Sample sites in Japan

\section{Chemical Treatment}

The collected leaves were initially washed by hand with normal water to remove the soils and extraneous contamination. After rinsed with ion-exchange water, they were successively treated with the hot solutions (ion-exchange water) of $1 \% \mathrm{HCI}$ for $1 \mathrm{hr}$ and $1 \% \mathrm{NaOH}$ for $1 \mathrm{hr}$, and then with the hot solution of $0.5 \% \mathrm{HCl}$ for $0.5 \mathrm{hr}$, all at $80{ }^{\circ} \mathrm{C}$ to remove the humic acid. After being rinsed with ion-exchange water, they were dried in an oven at $105^{\circ} \mathrm{C}$ overnight. Then the sample was heated at $800{ }^{\circ} \mathrm{C}$ for $1 \mathrm{hr}$ without air access. Thus the sample was converted to charcoal. The charcoal was reacted with metallic lithium at $860{ }^{\circ} \mathrm{C}$ for $1 \mathrm{hr}$ to produce lithium carbide. Lithium carbide was decomposed with ion-exchange water, producing acetylene. Then, benzene was synthesized from 
acetylene by using the vanadium-alumina-silica $\left(\mathrm{V}_{2} \mathrm{O}_{5}-\mathrm{Al}_{2} \mathrm{O}_{3}-\mathrm{SiO}_{2}\right)$ catalyst (Arslanov et al. 1993). The benzene was purified with sulfuric acid and cleaned by vacuum sublimation. Butyl-PBD $(15 \mathrm{~g} / \mathrm{L})$ was dissolved into the benzene to make a benzene scintillator $(10$ and $15 \mathrm{~mL})$.

\section{Liquid Scintillation Counting System}

A liquid scintillation counting system has been used for ${ }^{14} \mathrm{C}$ measurement of leaf samples. The design of the system is based on the previous system (Muraki et al. 1998) but some improvement has been done. Two photomultipliers (HAMAMATSU R351 with a quartz window of 2 inches in diameter and low noise) are used in coincidence mode to detect photons from the scintillator. The vial and the photomultipliers are placed inside a shielding box. The thickness of lead for the massive shield is $10 \mathrm{~cm}$. Inside the lead shield, placed are ${ }^{60} \mathrm{Co}$-free iron of $5 \mathrm{~cm}$ thick, OFHC copper plate of $1 \mathrm{~mm}$ thick and plastic scintillators of $2 \mathrm{~cm}$ thick for rejection of charged particles passing through in anti-coincidence mode. We do not use any cosmic neutron shield. No other selection of materials inside the shield was done for low background.

The signals from two photomultipliers are amplified with a fast amplifier module (ORTEC FT820A) and divided with a fan-out module (LeCroy 428F) into two signals, one for the discriminator for the logic circuit and the other for the pulse height measurement with ADC (LeCroy 2249W). A CAMAC system is used for ADC control. Two signals from both photomultipliers are summed by the software. The counter system and the electronics are placed in a temperature-controlled $\left( \pm 0.1^{\circ} \mathrm{C}\right)$ and electromagnetically shielded room.

Sample vials are made of Teflon for the body and pure copper for the cap, which were supplied by Wallac Co. The light collecting efficiency of individual vials was measured using the same ${ }^{14} \mathrm{C}$ standard benzene. The standard deviation of the efficiency for 5 vials used in this work is $0.28 \%$.

The background counting rate (B) is $3.7 \mathrm{cpm}$ and the counting rate for the modern standard $(0.7459$ of new NBS Standard activity) is $101 \mathrm{cpm}$ in the selected stable counting channel region for $15 \mathrm{~mL}$ of benzene in a $20 \mathrm{~mL}$ Teflon vial. The counting efficiency (E) is $61 \%$ and the Figure of Merit $\left(=\mathrm{E}^{2} /\right.$ B) is 1010. In our measurements, the benzene produced at the Geological Russia Institute of Russian Academy of Sciences and calibrated at St. Petersburg University (Arslanov et al. 1993), which is hereafter called the Russian Standard, was used as a standard. The $\delta^{14} \mathrm{C}$ values of samples were calculated by using the ratio of the activity of the Russian Standard and that of the Modern Standard, which is $5.0128 \pm 0.0107$ (Arslanov et al. 1993), as follows,

$$
\begin{gathered}
\delta^{14} \mathrm{C}(\% o)=1000\left(\mathrm{~A}_{\mathrm{s}}-\mathrm{A}_{\mathrm{abs}}\right) / \mathrm{A}_{\mathrm{abs}}, \\
\mathrm{A}_{\mathrm{abs}}=\mathrm{e}^{\lambda(\mathrm{y}-1950)} \mathrm{A}_{\mathrm{R}} / 5.0128
\end{gathered}
$$

where $A_{s}$ is the measured sample activity, $A_{a b s}$ the absolute international standard activity, $A_{R}$ the measured activity of the Russian standard, $\lambda\left(=\ln 2 / 5730=1.21010^{-4} \mathrm{yr}^{-1}\right)$ the decay constant of ${ }^{14} \mathrm{C}$ and $\mathrm{y}(=2000)$ the year when the sample was measured.

Typical counting scheme was as follows. First, the activity of the Russian Standard is measured for $22 \mathrm{hr}$, then the background is measured for $22 \mathrm{hr}$ using industrially produced dead benzene of spectral grade (Dojin Chemical Co., Japan). After that, two measurements of $15 \mathrm{~mL}$ sample benzene produced from leaves are measured for $22 \mathrm{hr}$ each. This scheme is repeated. A typical statistical error of the measurement was about $0.3 \%$. For a smaller quantity such as $10 \mathrm{~mL}$, which was caused by small amount of original leaves, counting time was prolonged to certain hours to assure almost the same statistical accuracy. Calculation of ${ }^{14} \mathrm{C}$ activity was carried out by using the sample counting 
rate together with the average counting rates of the two nearest measurements of the Russian standard and the dead benzene.

The counting system was tested with the IAEA intercomparison samples. The values of $\delta^{14} \mathrm{C}$ were measured in the same scheme as that for leaf samples. Results are shown in Table 1. We did not measure $\delta^{13} \mathrm{C}$ and used the consensus values (Rozanski et al. 1992) for fractionation correction. The obtained values of $\Delta^{14} \mathrm{C}$ and the consensus values (Rozanski et al. 1992) are expressed in pMC (per cent modern carbon). The rightmost column in the table shows the deviation of our value to the consensus value in a unit of $\sigma$, which is the squared sum of the measurement error and that of the consensus value listed in the table. The measured values of ${ }^{14} \mathrm{C}$ activity for the samples of $\mathrm{C}-2$ through C-6 agreed well with the consensus values within the errors.

The long-term stability was checked by time variation for the counting rates of the Russian standard. The standard deviation of 36 measurements for $15 \mathrm{~mL}$ benzene over 5 months was about $0.27 \%$.

Table 1 Measurement of IAEA intercomparison samples

\begin{tabular}{lrrr}
\hline Sample & \multicolumn{1}{c}{\begin{tabular}{c}
\multicolumn{1}{c}{$\begin{array}{c}\Delta^{14} \mathrm{C} \\
\mathrm{pMC})\end{array}$} \\
C-2
\end{tabular}$\quad \begin{array}{c}\text { Consensus value } \\
(\mathrm{pMC})\end{array}$} & $\begin{array}{c}\text { Deviation } \\
(\sigma)\end{array}$ \\
$\mathrm{C}-3$ & $129.83 \pm 0.35$ & $41.14 \pm 0.03$ & 1.2 \\
$\mathrm{C}-4$ & $0.24 \pm 0.09$ & $129.41 \pm 0.06$ & 1.3 \\
$\mathrm{C}-5$ & $23.01 \pm 0.23$ & $23.05 \pm 0.44$ & 0.4 \\
$\mathrm{C}-6$ & $150.70 \pm 0.50$ & $150.61 \pm 0.11$ & -0.2 \\
\hline
\end{tabular}

\section{RESULTS AND DISCUSSION}

Table 2 shows the details of the sampling site, together with the measured $\delta^{14} \mathrm{C}$ values. Listed in the table are the name of the site where the samples of the leaves were collected, geographic location (latitude, longitude, and altitude in above-sea-level), the kind of leaves and the feature of the site. The values of $\delta^{14} \mathrm{C}$ (in \%o) for the period of 1997 to 1999 are listed also in the table and are plotted in Figure 2. The ${ }^{14} \mathrm{C}$ contents are not corrected for the isotope fractionation. According to a literature (Stuiver and Polach 1977), the value of $\delta^{13} \mathrm{C}$ for tree leaves ranges from -25 to $-29 \%$ relative to that of the PDB standard. Therefore, we used the value of $\delta^{14} \mathrm{C}$ as the $\Delta^{14} \mathrm{C}$, assuming the $\delta^{13} \mathrm{C}$ values of the leaves are $-25 \%$. Values of $\delta^{13} \mathrm{C}$ will be measured for more accurate discussions.

Comparing the $\delta^{14} \mathrm{C}$ values in various areas, high ${ }^{14} \mathrm{C}$ concentrations $\left(80-100 \%\right.$ as $\left.\delta^{14} \mathrm{C}\right)$ are seen for the leaves collected at mountain areas in Nagano and those at country site in Hokkaido, while low concentrations (5-40\%o) were observed for the leaves from the city, especially near the roads with heavy traffic. This result indicates that the atmospheric carbon dioxide in the city sites is significantly diluted by the fossil dead carbon.

An excess of ${ }^{14} \mathrm{C}$ for the leaves from Agematsu and Norikura mountain areas was $90-100 \%$ in 1997-1999. The $\Delta^{14} \mathrm{C}$ value at Schauinsland in Central Europe was $104 \%$ in 1996, which was almost the same as those in the clean sites (Levin and Kromer 1997). Comparing the present values of mountain sites with those in the Central Europe, it is supposed that the atmosphere of the mountain sites in Japan is also clean and ${ }^{14} \mathrm{C}$ produced by nuclear bomb tests in the 1960 s is still observed. According to our previous data (Muraki et al. 1998) and those by other investigators (McNeely 1994; Levin and Kromer 1997; Krajcar-Bronić et al. 1998), the decreasing rate of ${ }^{14} \mathrm{C}$ contents in recent years is about 7\% per year. In order to see more precise variation, the monitor of leaves will 
Table 2 List of sampling sites and radiocarbon contents $\delta^{14} \mathrm{C}(\% \circ)$ for the period $1997-1999^{a}$

\begin{tabular}{|c|c|c|c|c|c|c|c|}
\hline Site ID & Location & Geographical location (asl) & Name of leaves & Feature & 1997 & 1998 & 1999 \\
\hline \multicolumn{8}{|c|}{ Tokyo region } \\
\hline $\mathrm{T} 1$ & Toyotama & $35^{\circ} 43^{\prime} \mathrm{N}, 139^{\circ} 39^{\prime} \mathrm{E}, 40 \mathrm{~m}$ & Zelkova serrata & HT, big city & - & $3.9 \pm 3.2$ & $5.9 \pm 4.3$ \\
\hline $\mathrm{T} 2$ & Nozawa & $35^{\circ} 38^{\prime} \mathrm{N}, 139^{\circ} 40^{\prime} \mathrm{E}, 20 \mathrm{~m}$ & Zelkova serrata & HT, big city & $26.4 \pm 3.2$ & $31.6 \pm 3.0$ & $23.6 \pm 3.2$ \\
\hline $\mathrm{T} 3$ & Zenpukuji & $35^{\circ} 43^{\prime} \mathrm{N}, 139^{\circ} 36^{\prime} \mathrm{E}, 50 \mathrm{~m}$ & Zelkova serrata & MT, suburbs & - & $41.4 \pm 3.2$ & $34.5 \pm 3.3$ \\
\hline $\mathrm{T} 4$ & Tanashi & $35^{\circ} 44^{\prime} \mathrm{N}, 139^{\circ} 33^{\prime} \mathrm{E}, 60 \mathrm{~m}$ & Magnolia kobus & MT, suburbs & $55.6 \pm 3.3$ & $58.0 \pm 3.2$ & $62.1 \pm 2.8$ \\
\hline T5 & Shakujii Park & $35^{\circ} 44^{\prime} \mathrm{N}, 139^{\circ} 36^{\prime} \mathrm{E}, 50 \mathrm{~m}$ & Carpinus tschonoskii & $\mathrm{P}$, suburbs & - & $64.0 \pm 3.2$ & $60.9 \pm 3.2$ \\
\hline \multicolumn{8}{|c|}{ Nagoya region } \\
\hline N1 & City Hall & $35^{\circ} 11^{\prime} \mathrm{N}, 136^{\circ} 54^{\prime} \mathrm{E}, 10 \mathrm{~m}$ & Zelkova serrata & MT, big city & - & $38.4 \pm 3.2$ & $53.5 \pm 3.2$ \\
\hline $\mathrm{N} 2$ & Nagoya Port & $35^{\circ} 02^{\prime} \mathrm{N}, 136^{\circ} 53^{\prime} \mathrm{E}, 0 \mathrm{~m}$ & Zelkova serrata & MT, big city & - & $49.8 \pm 3.2$ & $47.5 \pm 3.8$ \\
\hline $\mathrm{N} 3$ & N.U. (Eng.) & $35^{\circ} 09^{\prime} \mathrm{N}, 136^{\circ} 58^{\prime} \mathrm{E}, 60 \mathrm{~m}$ & Quercus variabilis & MT, suburbs & $64.1 \pm 3.5$ & $54.3 \pm 3.2$ & $63.2 \pm 3.3$ \\
\hline N4 & N.U. (STEL) & $35^{\circ} 09^{\prime} \mathrm{N}, 136^{\circ} 58^{\prime} \mathrm{E}, 70 \mathrm{~m}$ & Quercus variabilis & $\mathrm{P}$, suburbs & - & $70.8 \pm 3.3$ & $66.7 \pm 3.2$ \\
\hline N5 & Ohdaka Park & $35^{\circ} 03^{\prime} \mathrm{N}, 136^{\circ} 58^{\prime} \mathrm{E}, 20 \mathrm{~m}$ & Quercus variabilis & P, suburbs & - & $59.1 \pm 3.3$ & $70.2 \pm 3.2$ \\
\hline N6 & Higashiyama & $35^{\circ} 09^{\prime} \mathrm{N}, 136^{\circ} 59^{\prime} \mathrm{E}, 70 \mathrm{~m}$ & Quercus variabilis & $\mathrm{P}$, suburbs & - & $69.6 \pm 3.2$ & $71.5 \pm 3.2$ \\
\hline S1 & Kawagoe, Mie & $35^{\circ} 00^{\prime} \mathrm{N}, 136^{\circ} 41^{\prime} \mathrm{E}, 0 \mathrm{~m}$ & Zelkova serrata & TPS, industrial & $61.2 \pm 3.2$ & $62.5 \pm 3.3$ & $62.3 \pm 3.1$ \\
\hline \multicolumn{8}{|c|}{ Country site (Hokkaido) } \\
\hline $\mathrm{H} 1$ & Asahikawa-1 & $43^{\circ} 46^{\prime} \mathrm{N}, 142^{\circ} 25^{\prime} \mathrm{E}, 130 \mathrm{~m}$ & Magnolia quinquepeta & MT, local city & - & $92.6 \pm 3.3$ & $90.9 \pm 3.3$ \\
\hline $\mathrm{H} 2$ & Asahikawa-2 & $43^{\circ} 46^{\prime} \mathrm{N}, 142^{\circ} 25^{\prime} \mathrm{E}, 130 \mathrm{~m}$ & Betula platyphylla & MT, local city & - & - & $82.1 \pm 3.3$ \\
\hline $\mathrm{H} 3$ & Asahikawa-3 & $43^{\circ} 46^{\prime} \mathrm{N}, 142^{\circ} 25^{\prime} \mathrm{E}, 130 \mathrm{~m}$ & Aesculus turbinata & MT, local city & - & - & $80.3 \pm 3.4$ \\
\hline \multicolumn{8}{|c|}{ Mountain region (Nagano) } \\
\hline M1 & Agematsu & $35^{\circ} 45^{\prime} \mathrm{N}, 137^{\circ} 34^{\prime} \mathrm{E}, 1300 \mathrm{~m}$ & Betula ermanii & NT & $86.1 \pm 3.3$ & - & $98.1 \pm 3.3$ \\
\hline M2 & Norikura & $36^{\circ} 07^{\prime} \mathrm{N}, 137^{\circ} 08^{\prime} \mathrm{E}, 1450 \mathrm{~m}$ & Quercus crispula & NT & $99.5 \pm 3.3$ & $91.8 \pm 3.3$ & $88.4 \pm 3.5$ \\
\hline
\end{tabular}

aN.U. = Nagoya University; HT = heavy traffic; MT = moderate traffic; NT = no traffic; $\mathrm{P}=$ park; TPS = thermal power station. 


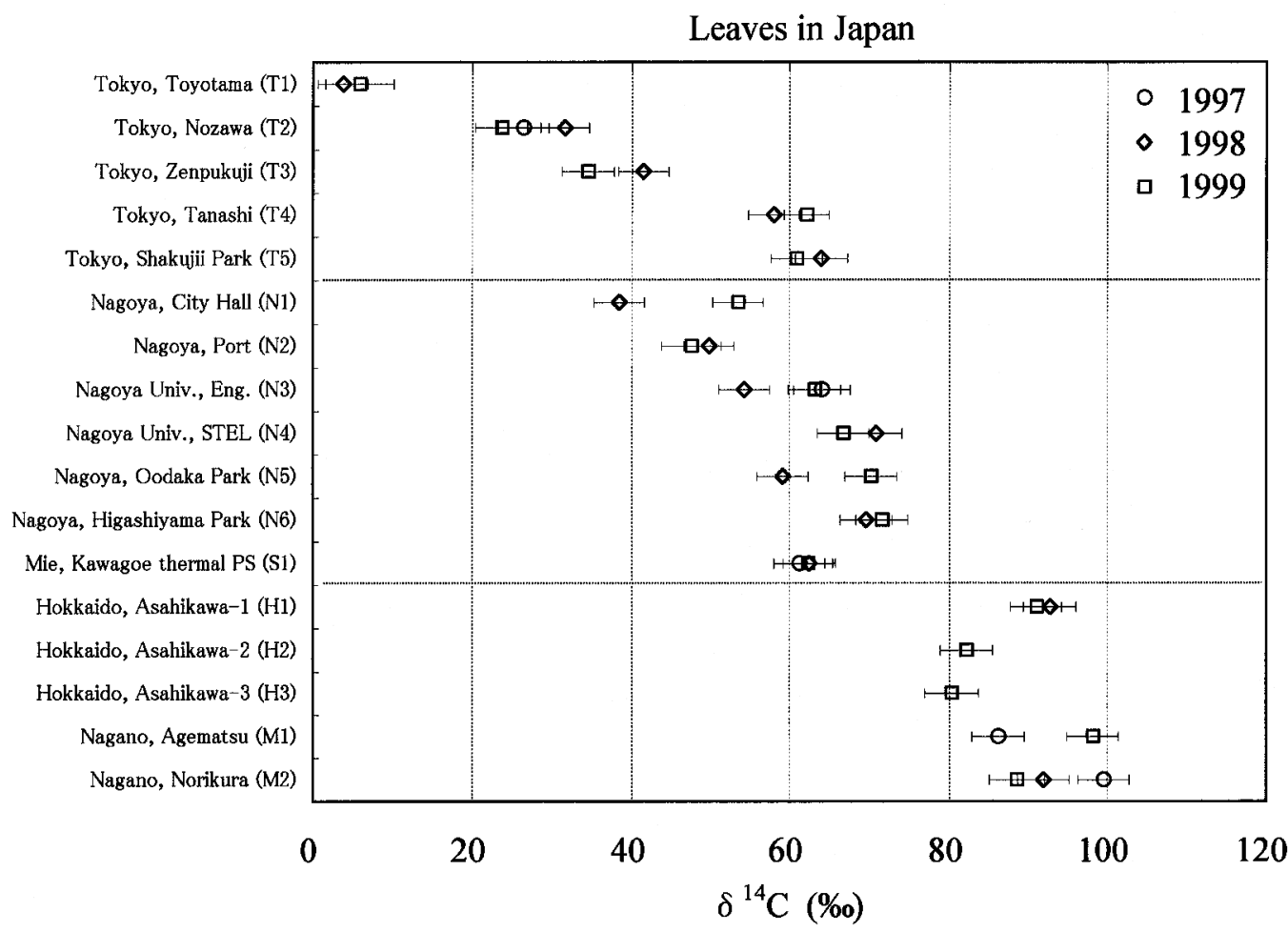

Figure 2 Radiocarbon contents $\delta^{14} \mathrm{C}(\%)$ in Japanese leaves

be continued. ${ }^{14} \mathrm{C}$ contents of tree rings will also be measured. In any case, it will take more than ten years for ${ }^{14} \mathrm{C}$ contents to reach the pre-bomb level of $\delta^{14} \mathrm{C}$.

The sampling site in Asahikawa is located on the outskirts of the city. The city itself is a middle scale in a basin of country site near a high mountain (Taisetsu-zan, $2290 \mathrm{~m}$ asl). It has neither heavy industries nor heavy traffic. This city would be classified into a clean site because $\delta^{14} \mathrm{C}$ value is almost the same as those of the mountain area. Leaves of three different kinds of trees (H1, H2, and H3) were collected at the same place within a few meters. These data represent almost the same values of $\delta^{14} \mathrm{C}$ and indicate that $\delta^{14} \mathrm{C}$ value of different kind of trees does not differ so much.

The $\delta^{14} \mathrm{C}$ values in the big cities such as Tokyo and Nagoya scatter very much, probably depending on the amount of traffic. At the sites with very heavy traffic, the $\delta^{14} \mathrm{C}$ value is quite low, indicating high concentration of fossil carbon dioxide. By a simple calculation, the concentration of $\mathrm{CO}_{2}$ in the worst case (T1) is 395 ppm assuming that the global average in clean air is $360 \mathrm{ppm}$ (Keeling et al. 1995; Levin et al. 1995; Nakazawa 1997; Nakazawa et al. 1997) and the carbon dioxide comes only from the fossil fuel consumption. If we know the exact $\mathrm{CO}_{2}$ concentration on the site, a fraction of fossil fuel-originated $\mathrm{CO}_{2}$ in all carbon dioxide can be derived. Some data show the $\mathrm{CO}_{2}$ concentration of 380-390 ppm in Tokyo area (Tokyo 1999; Komeiji et al. 1999). This is consistent with the above estimation. So, almost all carbon dioxide comes from the fossil fuel. In other sites of the cities, $\delta^{14} \mathrm{C}$ value is not so low, indicating that increase in the concentration of carbon dioxide is moderate.

In such a way, measurements of radiocarbon contents can tell us the average $\mathrm{CO}_{2}$ concentration. In order to confirm the precise relation between $\delta^{14} \mathrm{C}$ value and true $\mathrm{CO}_{2}$ concentration, it is needed to 
measure $\mathrm{CO}_{2}$ concentration in the sampling sites for several months. However, direct measurement of carbon dioxide or other pollutant molecules is very hard to be done. The present method to measure $\delta^{14} \mathrm{C}$ values in leaves is rather easy to estimate the concentration of carbon dioxide. Also the measurement of $\delta^{13} \mathrm{C}$ is very helpful to know the origin of carbon dioxide.

\section{CONCLUSION}

The measurement of $\delta^{14} \mathrm{C}$ contents in tree leaves clearly indicates the excess of $\mathrm{CO}_{2}$ concentration in city region, while there exists clean air in the country site as well as the mountain areas in Japan. The continuous measurement of tree leaves will tell us how the contents of atmospheric radiocarbon change and our environment is going to change. This method gives a good environmental monitor. The measurements must be continued further.

\section{ACKNOWLEDGMENTS}

This work was partly supported by Grant-in-Aid for Scientific Research (B) from Japan Society for the Promotion of Science.

\section{REFERENCES}

Arslanov KhA, Tertychnaya TV, Chernov SB. 1993. Problems and methods of dating low-activity samples by liquid scintillation counting. Radiocarbon 35(3): 393-8.

Keeling CD, Whorf TP, Wahlen M, van der Plicht J. 1995. Interannual extremes in the rate of rise of atmospheric carbon dioxide since 1980. Nature 375:666-9.

Komeiji T, Soufuku M, Sueoka S, Izumikawa S, Yoshioka H, Akiyama K, Yokota H, Sugiyama T, Iwasaki Y. 1999. Characteristic of carbon dioxide concentration in urban area. The Tokyo Metropolitan Research Institute for Environmental Protection Annual Report 98

Krajcar-Bronić I, Horvatinčić N, Obelić B. 1998. Two decades of environmental isotope records in Croatia, Reconstruction of the past and prediction of future levels. Radiocarbon 40(1):399-416.

Kuc T, Zimnoch M. 1998. Changes of the $\mathrm{CO}_{2}$ sources and sinks in a polluted urban area (southern Poland) over the last decade, derived from the carbon isotope composition. Radiocarbon 40(1):417-23.

Leung PL, Stokes MJ, Qiu SH, Cai LZ. 1995. A survey of environmental ${ }^{14} \mathrm{C}$ levels in Hong Kong. Radiocarbon 37(2):505-8.

Levin I, Graul R, Trivett NBA. 1995. Long-term observations atmospheric $\mathrm{CO}_{2}$ and carbon isotopes at continental sites in Germany. Tellus 47B:23-34.

Levin I, Kromer B. 1997. Twenty years of atmospheric ${ }^{14} \mathrm{CO}_{2}$ observations at Schauinsland station, Germany. Radiocarbon 39(2):205-18.

McNeely R. 1994. Long-term environmental monitoring of ${ }^{14} \mathrm{C}$ levels in the Ottawa region. Environment International 20(5):675-9.

Meijer HAJ, van der Plicht J, Gislefoss JS, Nydal R. 1995. Comparing long-term atmospheric ${ }^{14} \mathrm{C}$ and ${ }^{3} \mathrm{H}$ records near Groningen, the Netherlands with Fruholmen, Norway and Izaña, Canary Islands ${ }^{14} \mathrm{C}$ stations. Radiocarbon 37(1):39-50.

Muraki Y, Kocharov G, Nishiyama T, Naruse Y, Murata T, Masuda K. 1998. The new Nagoya radiocarbon laboratory. Radiocarbon 40(1):177-82.

Nakazawa T. 1997. Variations of carbon dioxide and methane in the atmosphere and their global cycles. Global Environmental Research 2(1):5-14.

Nakazawa T, Morimoto S, Aoki S, Tanaka M. 1997. Temporal and spatial variations of the carbon isotopic ratio of atmospheric carbon dioxide in the western Pacific region. Journal of Geophysical Research 102(D1): 1271-85.

Nydal R, Lövseth K. 1996. Carbon-14 measurements in atmospheric $\mathrm{CO}_{2}$ from Northern and Southern Hemisphere sites, 1962-1993. Oak Ridge National Laboratory NDP-057.

Rozanski K, Stichler W, Gonfiantini R, Scott EM, Beukens RP, Kromer B, van der Plicht J. 1992. The IAEA ${ }^{14} \mathrm{C}$ intercomparison exercise 1990. Radiocarbon 34(3):506-19.

Stuiver M, Polach H. 1977. Discussion: reporting of ${ }^{14} \mathrm{C}$ data. Radiocarbon 19(3):355-63.

Tokyo. 1999. http://www.kankyoken.koto.tokyo.jp/ chikyu/co2.htm. 